\title{
PRÓ-VITAMINAS A EM HORTALIÇAS COMERCIALIZADAS NO MERCADO FORMAL E INFORMAL DE VIÇOSA (MG), EM TRÊS ESTAÇÕES DO ANO'
}

\author{
Flávia Milagres CAMPOS ${ }^{2}$, Helena Maria PINHEIRO-SANT’ANA ${ }^{4, *}$, Patrícia Matias de SOUZA², \\ Paulo César STRINGHETA ${ }^{5}$, José Benício Paes CHAVES ${ }^{5}$
}

\begin{abstract}
RESUMO
Para fornecer dados sobre a influência climática e a forma de comercialização sobre carotenóides de vegetais, este estudo pesquisou o conteúdo de $\alpha$ e $\beta$-caroteno e o valor de vitamina A de sete hortaliças (batata-doce, cenoura, moranga, pimentão, quiabo, tomate e vagem), na cidade de Viçosa (MG), utilizando a Cromatografia Líquida de Alta Eficiência. Compararam-se hortaliças comercializadas nos mercados formal (mercados locais) e informal (feira livre) durante primavera, verão e outono. A cenoura apresentou os teores mais elevados de $\alpha$ e $\beta$-caroteno (31,17 e 58,18 $\mu \mathrm{g} / \mathrm{g}$, respectivamente), seguida pela moranga (4,33 e $23,16 \mu \mathrm{g} / \mathrm{g}$, respectivamente), enquanto a batata-doce apresentou o teor mais reduzido de $\beta$-caroteno $(0,51 \mu \mathrm{g} / \mathrm{g})$. O valor de vitamina A variou conforme o perfil de $\alpha$ e $\beta$-caroteno. Com exceção da cenoura e do quiabo, não houve influência significativa do local de comercialização sobre o conteúdo de carotenóides. A variação do conteúdo de carotenos nas estações do ano foi inexpressiva, sendo que apenas o pimentão apresentou valores significativamente diferentes. Porções de $100 \mathrm{~g}$ das hortaliças analisadas fornecem entre 3 e $78 \%$ da recomendação de vitamina A.

Palavras-chaves: $\beta$-caroteno, $\alpha$-caroteno, hortaliças, mercados, feira livre, estações do ano.
\end{abstract}

\section{SUMMARY}

PROVITAMINS A IN VEGETABLES MARKED IN FORMAL AND FREE MARKET AT VIÇOSA (MG), BRAZIL, DURING THREE SEASONS OF THE YEAR. With the aim of providing data on the influence of climate and form of commercialization on carotenoid of vegetables, this study evaluate the content of $\alpha$ and $\beta$ carotene and vitamin A value of seven vegetables (sweet potato, carrot, squash, green pepper, okra, tomato and green bean) market in Viçosa (MG), Brazil, using High Performance Liquid Chromatography (HPLC). It was compared vegetables commercialized in two local markets and in the free market during spring, summer and autumn. Carrot presented the highest values of $\alpha$ and $\beta$-carotene ( 31.17 e $58.18 \mu \mathrm{g} / \mathrm{g}$, respectively), followed by squash (4.33 and $23.16 \mu \mathrm{g} / \mathrm{g}$, respectively), while sweet potato presented the lowest value of $\beta$ carotene $(0.51 \mu \mathrm{g} / \mathrm{g})$. The vitamin A values varied as the profile of $\alpha$ and $\beta$-carotene content. The results showed that, except for carrot and okra, there was no significant influence of the market type on the content of carotenoids. The variation of the content of $\alpha$ and $\beta$-carotene in the seasons was not important, and only green pepper presented significantly different values. Portions of $100 \mathrm{~g}$ of analyzed vegetables supply 3 to $78 \%$ of vitamin A recommendation. Keywords: $\beta$-carotene, $\alpha$-carotene, vegetables, markets, free markets, seasons.

\section{1 - INTRODUÇÃO}

Os carotenóides vêm sendo estudados sob vários aspectos, especialmente, no que diz respeito à sua ação fisiológica e à sua qualificação e quantificação, em razão da sua larga presença em hortaliças e frutas e variedade de arranjos estruturais que levam a uma diversidade de funções.

Eles têm sua principal função atribuída à capacidade de conversão em vitamina A, cujas funções no organismo

\footnotetext{
${ }^{1}$ Recebido para publicação em 11/6/2004. Aceito para publicação em 23/1/2006 (001363)

${ }^{2}$ Bolsista do Pibic/CNPq, Nutricionista pela Universidade Federal de Viçosa (UFV)

${ }^{3}$ Nutricionista pela Universidade Federal de Viçosa (UFV)

${ }^{4}$ Prof ${ }^{a}$. do Departamento de Nutrição e Saúde. Universidade Federal de Viçosa (MG)

Campus Universitário, $s / n^{\circ}$

CEP 36571-000 - Viçosa (MG)

E-mail: helena.santana@.ufv.br,sepriore@mail.ufv.br

Tel.: (31) 3899-1266 / Fax: (31) 3899-2541

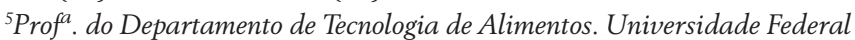
de Viçosa (UFV)

*A quem a correspondência deve ser enviada

Apoio financeiro: Programa Institucional de Bolsas de Iniciação Científica (Pibic) - Conselho Nacional de Desenvolvimento Científico e Tecnológico (CNPq)
}

estão relacionadas à visão, ao crescimento ósseo e à diferenciação de tecidos [12, 15]. Estimativas recentes indicam que, mundialmente, mais de 2 milhões de pessoas têm risco de desenvolver deficiência de vitamina $A$, apesar de recentes esforços na prevenção e controle. A prevalência é especialmente alta no sudeste da Ásia e na região do Saara, na África $[17,28]$. Os dados dos últimos 20 anos indicam que a deficiência de vitamina A é um problema de saúde pública no Brasil [26], principalmente nas regiões do Norte, Nordeste e Sudeste. De acordo com RAMALHO et al. [18], os inquéritos bioquímicos disponíveis no País confirmam que a deficiência de vitamina A é um problema de saúde pública nos Estados de São Paulo, Minas Gerais, Pernambuco, Paraíba, Bahia e Amazonas.

Apesar do valor de vitamina A dos vegetais ter caído à metade com a utilização dos novos fatores de conversão de carotenóides pró-vitamínicos propostos pelo Institute of Medicine, eles ainda representam fonte significativa da vitamina, especialmente em populações em risco de desenvolver a deficiência [12].

Atualmente, a ação dos carotenóides na prevenção e tratamento de patologias como câncer, doenças cardiovasculares, catarata, desordens fotossensíveis e do sistema imunológico, tem atraído ainda mais a atenção dos pes- 
quisadores. Em virtude do seu potencial antioxidante e de seu papel no desenvolvimento e na diferenciação celular, os carotenóides podem proteger o organismo de desordens degenerativas. Várias evidências epidemiológicas associam a ingestão de uma dieta rica em carotenóides e alta concentração tecidual destes com redução do risco de câncer [4, 27, 30].

Frente a todas essas ações benéficas e possibilidades no emprego dos carotenóides, torna-se imprescindível a quantificação destes nos alimentos. Para atender às necessidades atuais, as tabelas de composição química dos alimentos devem trazer o conteúdo de carotenóides e não apenas o valor de vitamina $\mathrm{A}$.

No entanto, embora as hortaliças sejam conhecidamente boas fontes de carotenóides, seu conteúdo é influenciado pela variedade, grau de maturação, condições de cultivo, estação do ano e pela parte da hortaliça que é consumida. Além disso, as condições de colheita, armazenamento e exposição para o consumidor podem alterar o conteúdo de carotenóides, tanto qualitativamente quanto quantitativamente, pela conversão na forma cis e degradação [1, 6, 9, 24]. Devido à diferente infra-estrutura existente nos mercados formais e nas feiras livres, o conteúdo de carotenóides das hortaliças pode variar, visto que estes pigmentos são instáveis à presença de luz, calor, metais e oxigênio, condições muitas vezes presentes no período entre a colheita e o consumo final [21].

O objetivo deste estudo é comparar o conteúdo $\alpha$ e $\beta$ caroteno em hortaliças comercializadas no mercado formal e informal e verificar a influência climática no conteúdo dos carotenóides. Além disso, visa fornecer dados sobre a atividade pró-vitamínica A destas hortaliças e contribuir para a melhor interpretação de estudos epidemiológicos que relacionam os carotenos e a saúde humana.

\section{2 - MATERIAL E MÉTODOS}

\section{1 - Amostras}

As hortaliças analisadas foram: batata-doce (Ipomoea batatas), cenoura (Daucus carota), moranga (Cucurbita spp.), pimentão (Capsicum annuum), quiabo (Abelmoschus esculentus), tomate (Lycopersicon esculentum) e vagem (Phaseolus vulgaris), coletadas em dois mercados formais e cinco barracas no mercado informal (feira livre), na cidade de Viçosa (MG), que se situa na região da Zona da Mata mineira, a 648,74 m de altitude.

As hortaliças comercializadas nos mercados eram provenientes da Central de Abastecimento (Ceasa) de Belo Horizonte (MG) ou de produtores da região, enquanto as hortaliças comercializadas na feira livre foram cultivadas na microrregião de Viçosa pelos próprios feirantes. Nos mercados locais as hortaliças eram armazenadas por cerca de $24 \mathrm{~h}$, à temperatura ambiente, e expostas à comercialização dentro do estabelecimento. Já na feira livre as hortaliças eram comercializadas, em geral, no mesmo dia da colheita e apresentadas para venda em bancas expostas ao sol ou simplesmente cobertas com lona.

As hortaliças foram coletadas nos estabelecimentos comerciais e na feira livre, de acordo com sua disponibilidade nos dias de coleta, procurando-se estabelecer três repetições em cada ponto de coleta, em cada estação do ano, como é apresentado na Tabela 1. O grau de maturação das hortaliças foi avaliado de acordo com a análise visual feita pelos pesquisadores. Escolheram-se hortaliças com grau de maturação médio, tanto nos mercados quanto na feira livre.

\section{2 - Tratamento das amostras}

Após a coleta, as hortaliças foram lavadas em água corrente e secas em papel toalha. Removeram-se, posteriormente, as partes não comestíveis, como pedúnculos e a porção mais externa da casca. Imediatamente após esse procedimento, as hortaliças foram picadas em pequenos pedaços para facilitar a trituração. O processo de extração foi realizado no mesmo dia da coleta das amostras.

\section{3 - Reagentes e outros materiais}

Para o preparo das amostras e padrões foram utilizados reagentes com grau de pureza para análise: acetona, éter de petróleo, éter etílico, sulfato de sódio anidro, hyflosupercel e óxido de magnésio. As fases móveis foram preparadas utilizando-se reagentes grau HPLC: metanol, acetonitrila, acetato de etila OmniSolv EM Science, USA. Para filtração das amostras foram empregados papel de filtro livre de

TABELA 1 - Hortaliças fornecidas pelos estabelecimentos durante três estações do ano

\begin{tabular}{|c|c|c|c|c|c|c|c|c|c|c|c|c|c|c|c|c|c|c|c|c|c|}
\hline \multirow[t]{3}{*}{ Hortaliça } & \multicolumn{7}{|c|}{ Primavera } & \multicolumn{7}{|c|}{ Verão } & \multicolumn{7}{|c|}{ Outono } \\
\hline & \multicolumn{2}{|c|}{ Mercados } & \multicolumn{4}{|c|}{ Feira } & \multirow[b]{2}{*}{5} & \multicolumn{2}{|c|}{ Mercados } & \multicolumn{4}{|c|}{ Feira } & \multirow[b]{2}{*}{5} & \multicolumn{2}{|c|}{ Mercados } & \multicolumn{5}{|c|}{ Feira } \\
\hline & 1 & 2 & 1 & 2 & 3 & 4 & & 1 & 2 & 1 & 2 & 3 & 4 & & 1 & 2 & 1 & 2 & 3 & 4 & 5 \\
\hline Batata-doce & $x$ & $x$ & $x$ & & & & $x$ & $x$ & & & & & & $x$ & $x$ & & & & & & $x$ \\
\hline Cenoura & $x$ & $x$ & $x$ & & & $x$ & & $x$ & $x$ & $x$ & & $x$ & $x$ & & $x$ & $x$ & $x$ & & $x$ & $x$ & \\
\hline Moranga & $x$ & $x$ & $x$ & & $x$ & & & $x$ & $x$ & $x$ & & $x$ & & & $x$ & $x$ & $x$ & & $x$ & & \\
\hline Pimentão verde & $x$ & $x$ & $x$ & & $x$ & & & $x$ & $x$ & $x$ & & & $x$ & & $x$ & $x$ & $x$ & $x$ & & $x$ & \\
\hline Quiabo & $x$ & $x$ & $x$ & & & & & $x$ & $x$ & $x$ & $x$ & & & & $x$ & $x$ & $x$ & & & $x$ & \\
\hline Tomate & $x$ & $x$ & $x$ & $x$ & & $x$ & & $x$ & $x$ & $x$ & $x$ & & $x$ & & $x$ & $x$ & $x$ & $x$ & & $x$ & \\
\hline Vagem & $x$ & $x$ & $x$ & $x$ & & $x$ & & $x$ & $x$ & & & & & & $x$ & $x$ & $x$ & $x$ & & $x$ & \\
\hline
\end{tabular}


cinzas e unidades filtrantes em polietileno com $0,45 \mu \mathrm{m}$ de porosidade Millipore, Brasil.

\section{4 - Extração dos carotenóides}

O processo de extração foi realizado segundo RODRIGUEZ et al. [19], com algumas modificações. Os pigmentos foram extraídos de cerca de $5 \mathrm{~g}$ de amostra por trituração com $80 \mathrm{~mL}$ de acetona e em seguida transferidos para $60 \mathrm{~mL}$ de éter de petróleo. A concentração do extrato foi feita em evaporador rotativo, na faixa de temperatura entre 35 e $37^{\circ} \mathrm{C}$. Em seguida, os carotenóides foram redissolvidos em $15 \mathrm{~mL}$ de éter de petróleo. Os pigmentos foram armazenados em frascos de vidro âmbar, em freezer a $-5^{\circ} \mathrm{C}$, até a análise dos carotenóides (cerca de 24 h).

\section{5 - Isolamento dos padrões de $\alpha$ e $\beta$-caroteno}

Os padrões ( $\alpha$ e $\beta$-caroteno) foram isolados de extrato concentrado de cenoura, por Cromatografia de Coluna Aberta, segundo RODRIGUEZ-AMAYA [22]. Cerca de $20 \mathrm{~g}$ de cenoura foram triturados com acetona e posteriormente transferidos para éter de petróleo, conforme descrito no item 2.4. Foi utilizada coluna cromatográfica empacotada com óxido de magnésio: hyflosupercel (1:2) e fase móvel composta por $2 \%$ de éter etílico em éter de petróleo. O extrato de cenoura foi utilizado na obtenção de padrões porque contém quantidades apreciáveis de $\alpha$ e $\beta$-caroteno. Os parâmetros usados para confirmar a identificação dos padrões foram: ordem de eluição das frações na coluna, coloração dos pigmentos eluídos, tempo de retenção em CLAE e espectros de absorção característicos. A pureza das soluções foi verificada por CLAE, e a quantificação foi realizada por Espectrofotometria, baseando-se na absorvância máxima, segundo a Lei de Beer. Os coeficientes de absortividade utilizados foram 2.800 para $\alpha$-caroteno e 2.592 para $\beta$-caroteno. Os comprimentos de onda de máxima absorção foram $\alpha: 444$ e $\beta: 450 \mathrm{~nm}$, em éter de petróleo [22].

\section{6 - Condições cromatográficas}

A análise baseou-se nas condições cromatográficas desenvolvidas por PINHEIRO-SANT'ANA et al. [16], com algumas modificações. Foram utilizados: cromatógrafo líquido de alta eficiência, modelo LC 10 AD, Shimadzu; Injetor manual, com loop de $50 \mu \mathrm{l}$; coluna Lichrospher
100, RP-18, $5 \mu \mathrm{m}, 250 \times 4 \mathrm{~mm}$; detector espectrofotométrico, UV-visível, modelo SPD 10 AV, Shimadzu, com detecção a $450 \mathrm{~nm}$; fase móvel - metanol: acetonitrila: acetato de etila (80:10:10); Fluxo: 2 mL/min.

\section{7 - Cálculo do valor de vitamina A}

O cálculo do valor de vitamina A foi feito segundo as novas recomendações do INSTITUTE OF MEDICINE [13], no qual o Equivalente de Retinol (RE) foi substituído pelo Equivalente de Atividade de Retinol (RAE). Com os novos fatores de conversão, a atividade vitamínica de carotenóides pró-vitamínicos passou a ser a metade da atividade de vitamina A quando se utilizava $\mu g$ de RE. Define-se que $1 \mathrm{RAE}$ equivale a $1 \mu \mathrm{g}$ de retinol, ou $12 \mu \mathrm{g}$ de $\beta$-caroteno, ou $24 \mu \mathrm{g}$ de $\alpha$-caroteno [12].

\section{8 - Análises estatísticas}

As análises estatísticas foram conduzidas utilizando-se o programa Statistical Analysis System (SAS) [25]. A análise de variância foi utilizada para verificar a existência de diferenças significativas entre os tipos de estabelecimentos e entre as estações do ano. O teste de Duncan foi empregado para analisar as médias que apresentaram diferenças significativas na análise de variância. Em ambas as análises utilizou-se um nível de significância de $5 \%(\alpha=0,05)$.

\section{3 - RESULTADOS E DISCUSSÃO}

$\mathrm{O} \alpha \mathrm{e} \beta$-caroteno foram detectados em todas as hortaliças analisadas, com exceção do tomate, no qual não houve detecção de $\alpha$-caroteno. Os picos dos carotenóides em análise e dos padrões apresentaram tempos de retenção muito próximos, indicando que o procedimento usado permitiu uma identificação confiável dos carotenóides.

Na Figura 1 são apresentados os cromatogramas típicos obtidos da análise de $\alpha$ e $\beta$-caroteno nas hortaliças avaliadas.

Nas amostras de batata-doce, embora tenha sido possível identificar o pico de $\alpha$-caroteno, este não pôde ser quantificado em virtude dos baixos níveis encontrados. Além disso, nas amostras de pimentão verde, quiabo e vagem o $\alpha$-caroteno não foi detectado em todas as amostras, e o cálculo das médias foi feito excluindo-se os resultados nulos.

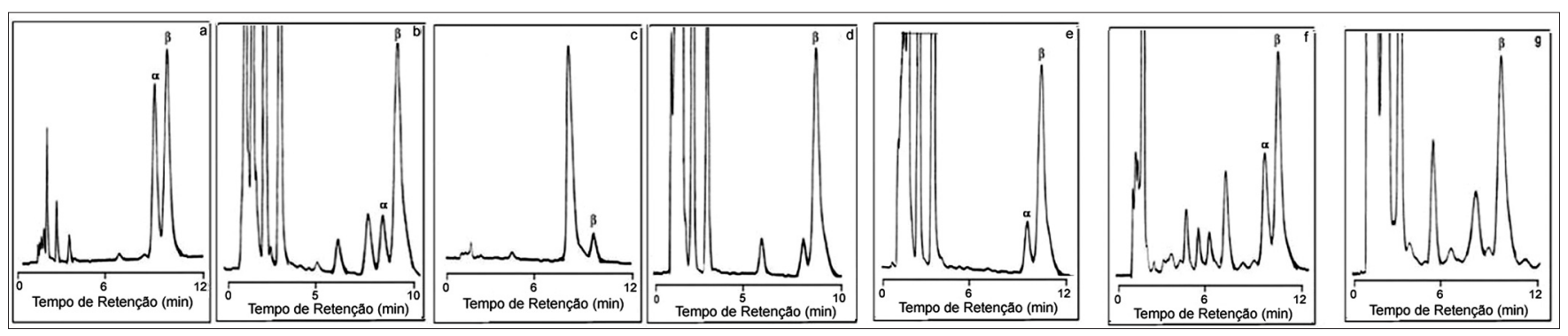

FIGURA 1 - Análise por CLAE de extratos de (a) cenoura, (b) pimentão verde, (c) tomate, (d) quiabo, (e) vagem, (f) moranga e (g) batata-doce. Condições cromatográficas descritas no texto. Identificação dos picos: $\alpha$ : $\alpha$-Caroteno; $\beta$ : $\beta$-Caroteno 
Os teores médios de $\alpha$ e $\beta$-caroteno nas amostras de hortaliças de acordo com as estações do ano (primavera, verão e outono) podem ser vistos nas Tabelas 2 e 3 . As amostras de batata-doce apresentaram 0,57 e $0,44 \mu \mathrm{g} / \mathrm{g}$ de $\beta$-caroteno em hortaliças provenientes de mercados formais e da feira livre, respectivamente, mostrando que as variedades comercializadas em Viçosa são pobres em $\beta$-caroteno. Em estudo realizado na cidade de São Paulo, batatas-doce de polpa branca apresentaram teor médio de $0,61 \mu \mathrm{g} / \mathrm{g}$ de $\beta$-caroteno [2]. BUREAU \& BUSHWAY [6], analisando batata-doce cultivada nos EUA, encontraram grande variação no valor de vitamina A em diferentes variedades (valores entre 0,30 e 33,80 $\mu \mathrm{g} \mathrm{RE} / \mathrm{g}$ ).

O conteúdo de carotenóides em batata-doce varia muito de um estudo para outro em razão da variedade analisada. Em geral, quanto mais clara for a polpa da batata, menor o conteúdo de carotenóides. K'OSAMBO et al. [14], em estudo feito no Quênia, encontraram valores de $\beta$-caroteno em batata-doce de polpa branca menores que $10 \mu \mathrm{g} / \mathrm{g}$, enquanto para as de polpa laranja, este valor foi de $80 \mu \mathrm{g} / \mathrm{g}$, em média.

Os resultados encontrados no presente estudo estão de acordo com os apresentados por HOLDEN et al. [11], no qual as melhores fontes de $\alpha$-caroteno foram cenoura, moranga e abóbora; enquanto o $\beta$-caroteno está presente em diversas hortaliças, sendo encontrado principalmente em hortaliças de cor laranja e verde-escura. Outros estudos relataram pequenas quantidades de $\alpha$-caroteno em quiabo e pimentão verde $(0,34 \mathrm{e} 0,28 \mu \mathrm{g} / \mathrm{g}$, respectivamente) [5], ou não o encontraram $[7,8,9]$. O estudo de BUREAU \&
BUSHWAY [5] indicou os seguintes valores médios para $\alpha$-caroteno em cenoura, vagem e moranga: 37,86; 0,64 e $0,12 \mu \mathrm{g} / \mathrm{g}$, respectivamente. $\mathrm{O} \alpha$-caroteno também não foi quantificado nas amostras de batata-doce. Além disso, foram encontrados os seguintes teores médios de $\beta$-caroteno: $76,02 \mu \mathrm{g} / \mathrm{g}$ em cenoura, 3,64 $\mu \mathrm{g} / \mathrm{g}$ em vagem, 2,17 $\mu \mathrm{g} / \mathrm{g}$ em pimentão verde, $4,31 \mu \mathrm{g} / \mathrm{g}$ em quiabo, $1,77 \mu \mathrm{g} / \mathrm{g}$ em moranga e $86,11 \mu \mathrm{g} / \mathrm{g}$ em batata-doce.

Em estudo realizado com morangas e abóboras da Região Nordeste, o valor médio de $\beta$-caroteno em Curcubita moschata da variedade "baianinha" foi $235 \mu \mathrm{g} / \mathrm{g}$, enquanto em Curcubita maxima da variedade "jerimum caboclo" este valor foi de $21 \mu \mathrm{g} / \mathrm{g}$ [3].

WILBERG \& RODRIGUEZ-AMAYA [29] obtiveram um teor médio de $\beta$-caroteno em tomates de $4,30 \mu \mathrm{g} / \mathrm{g}$, o qual está de acordo com este estudo. Outros estudos também mostram valores de $\beta$-caroteno, para as hortaliças em análise, próximos aos teores encontrados neste estudo [7, $8,13]$. As variações encontradas provavelmente se devem à variedade de estudo, safra, grau de maturação e local da coleta.

Como não foi possível controlar as variedades das hortaliças em estudo, uma vez que este foi realizado em condições reais (simulando a compra das hortaliças pelos consumidores), e não com hortaliças produzidas de forma padronizada, as variedades podem ter influenciado na variação do conteúdo de $\alpha$ e $\beta$-caroteno das hortaliças.

Com exceção do pimentão verde, a análise de variância do conteúdo de $\alpha$ e $\beta$-caroteno não detectou diferença significativa $(P \geq 0,05)$ entre as três estações do ano. No outono, o

TABELA 2 - Teores médios ${ }^{1}$ de $\alpha$-caroteno $(\mu \mathrm{g} / \mathrm{g})$ em amostras de hortaliças comercializadas em Viçosa, durante três estações do ano ${ }^{2}$

\begin{tabular}{|c|c|c|c|c|c|c|}
\hline \multirow[t]{2}{*}{ Hortaliça } & \multicolumn{2}{|c|}{ Primavera } & \multicolumn{2}{|l|}{ Verão } & \multicolumn{2}{|l|}{ Outono } \\
\hline & $\alpha$-caroteno & $n^{3}$ & $\alpha$-caroteno & $\mathrm{n}$ & $\alpha$-caroteno & $\mathbf{n}$ \\
\hline Cenoura & $33,38 \mathrm{a}(21,43)$ & 12 & $36,46 a(16,50)$ & 15 & $23,66 a(15,41)$ & 15 \\
\hline Pimentão verde & $0,45 a(0,37)$ & 9 & $0,46 a(0,31)$ & 8 & $0,53 a(0,36)$ & 12 \\
\hline Quiabo & $0,55 a(0,2)$ & 5 & $0,37 a(0,27)$ & 11 & $0,43 a(0,22)$ & 6 \\
\hline
\end{tabular}

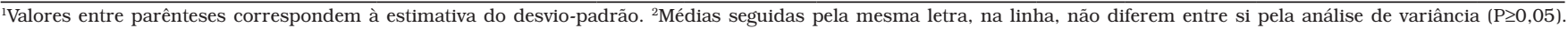
${ }^{3} \mathrm{n}=$ número de determinações

TABELA 3 - Teores médios ${ }^{1}$ de $\beta$-caroteno $(\mu \mathrm{g} / \mathrm{g})$ em amostras de hortaliças comercializadas em Viçosa, durante três estações do ano ${ }^{2}$

\begin{tabular}{|c|c|c|c|c|c|c|}
\hline \multirow[t]{2}{*}{ Hortaliça } & \multicolumn{2}{|c|}{ Primavera } & \multicolumn{2}{|l|}{ Verão } & \multicolumn{2}{|l|}{ Outono } \\
\hline & $\beta$-caroteno & $n^{4}$ & $\beta$-caroteno & n & $\beta$-caroteno & $\mathbf{n}$ \\
\hline Batata-doce $^{2}$ & $0,59 a(0,53)$ & 12 & $0,39 a(0,18)$ & 11 & $0,54 a(0,27)$ & 7 \\
\hline Cenoura $^{2}$ & $57,11 \mathrm{a}(24,51)$ & 12 & $65,93 a(24,47)$ & 15 & $51,51 \mathrm{a}(32,32)$ & 15 \\
\hline Moranga $^{2}$ & $21,07 a(7,81)$ & 11 & $24,27 \mathrm{a}(12,87)$ & 12 & $24,13 \mathrm{a}(8,21)$ & 12 \\
\hline Pimentão verde 3 & $3,76 b(1,14)$ & 12 & $4,39 a b(0,80)$ & 12 & $5,27 a(1,31)$ & 15 \\
\hline Quiabo² $^{2}$ & $3,57 \mathrm{a}(1,44)$ & 9 & $4,25 a(1,75)$ & 14 & $3,37 \mathrm{a}(1,19)$ & 8 \\
\hline Tomate $^{2}$ & $5,83 a(1,37)$ & 15 & $5,58 a(1,39)$ & 15 & $6,84 a(3,26)$ & 15 \\
\hline Vagem $^{2}$ & $3,74 a(0,95)$ & 14 & $5,60 \mathrm{a}(2,39)$ & 6 & $4,09 a(1,28)$ & 15 \\
\hline
\end{tabular}

Valores entre parênteses correspondem à estimativa do desvio-padrão. ${ }^{2}$ Médias seguidas pela mesma letra, na linha, não diferem entre si pela análise de variância (P $\left.\geq 0,05\right)$. ${ }^{3}$ Médias seguidas pela mesma letra, na linha, não diferem entre si pelo teste de Duncan $(P \geq 0,05) .{ }^{4} n=$ número de determinações 
pimentão verde apresentou teores significativamente mais elevados de $\beta$-caroteno, enquanto na primavera a hortaliça apresentou os teores mais reduzidos (uma redução de cerca de $40 \%$ ).

Diferentemente, GRANADO et al. [8] observaram variação na concentração de carotenóides de várias hortaliças de acordo com as quatro estações do ano e também na mesma estação em anos consecutivos. Da mesma forma, um estudo feito por HEINONEN et al. [10] indicou variação no conteúdo de $\alpha$ e $\beta$-caroteno em cenoura, alface e tomate analisados em diferentes estações do ano. Estes resultados diferentes dos encontrados neste trabalho podem ser explicados pelo fato de que estes estudos foram realizados no continente europeu (Espanha e Finlândia, respectivamente), onde o clima é temperado e as estações do ano são marcadas por diferenças climáticas significativas. Já na região da cidade de Viçosa, o clima é tropical, não havendo grandes diferenças climáticas entre as três estações do ano estudadas. Nota-se que as estações "intermediárias" (primavera e outono) não são marcadamente diferentes, ou seja, basicamente apenas duas estações no ano apresentam diferenças climáticas mais marcantes (verão, quente e úmido; e inverno, frio e seco).

Os conteúdos de $\alpha$ e $\beta$-caroteno nas amostras de hortaliças estudadas, de acordo com o estabelecimento de coleta, são apresentados na Tabela 4.

Os teores de $\alpha$ e $\beta$-caroteno encontrados nas amostras de cenoura coletadas nos mercados foram estatisticamente superiores aos encontrados para as amostras provenientes da feira livre (uma diferença de cerca de 25 a $35 \%$, respectivamente). Já as amostras de quiabo coletadas nos mercados locais apresentaram valores de $\beta$-caroteno estatisticamente inferiores (em torno de 61\%) aos encontrados para amostras provenientes da feira livre. Para as demais hortaliças, embora tenha havido variação nos teores de $\alpha$ e $\beta$-caroteno de acordo com o tipo de mercado, estas variações não foram estatisticamente significantes.

As variações no conteúdo de $\alpha$ e $\beta$-caroteno podem ter sido causadas por diversos fatores, entre eles o fato de que na feira livre, em geral, as hortaliças ficam expostas ao sol, o que pode ter contribuído para a degradação dos carotenóides. Já nos mercados, as hortaliças podem ficar armazenadas por cerca de 24 h, em ambiente não refrigerado, até a sua comercialização. Além disso, o grau de maturação das hortaliças pode influenciar bastante no conteúdo de carotenóides. Em várias frutas, o amadurecimento é acompanhado de um aumento na carotenogênese, enquanto a clorofila é degradada e os cloroplastos são convertidos em cromoplastos [23]. No entanto, não parece ter sido este o principal fator a influenciar a diferença nos valores entre os mercados e feira livre, pois ambos estavam sujeitos à escolha do pesquisador. As hortaliças eram escolhidas de forma a representar o lote do qual provinham.

Outro fato que deve ser lembrado é que, certamente, carotenóides de hortaliças distintas resistem de forma diferente aos fatores que podem causar sua degradação (calor, variações de $\mathrm{pH}$, oxigênio, luz). Dependendo da estrutura da hortaliça, pode haver menor ou maior degradação dos carotenóides. Por exemplo, é prática comum, tanto nos mercados locais quanto na feira livre, cortar a moranga ao meio durante a exposição da hortaliça para comercialização. Esta prática expõe mais a polpa da hortaliça ao oxigênio e à luz, podendo aumentar a degradação dos carotenóides. Quanto mais tempo a hortaliça permanece exposta dessa forma, maiores são as chances de perda de carotenóides.

Os carotenóides das hortaliças que permanecem armazenadas nos mercados podem sofrer a influência da temperatura e do tempo de transporte e armazenamento, uma vez que boa parte das hortaliças é adquirida da Central de Abastecimento (Ceasa) de Belo Horizonte. O quiabo mostrou-se menos resistente às condições de transporte e armazenamento nos mercados.

A Tabela 5 mostra a contribuição de cada pró-vitamina A para o valor de vitamina A total, e a Figura 2 apresenta o valor de vitamina A total das hortaliças nas três estações estudadas; valores em porcentagem representam a adequação de vitamina A para $100 \mathrm{~g}$ da hortaliça A porcentagem de adequação de vitamina A presente em uma porção de

TABELA 4 - Teores médios de $\alpha$ e $\beta$-caroteno ( $\mu \mathrm{g} / \mathrm{g})$ em amostras de hortaliças comercializadas em Viçosa ${ }^{1,2}$

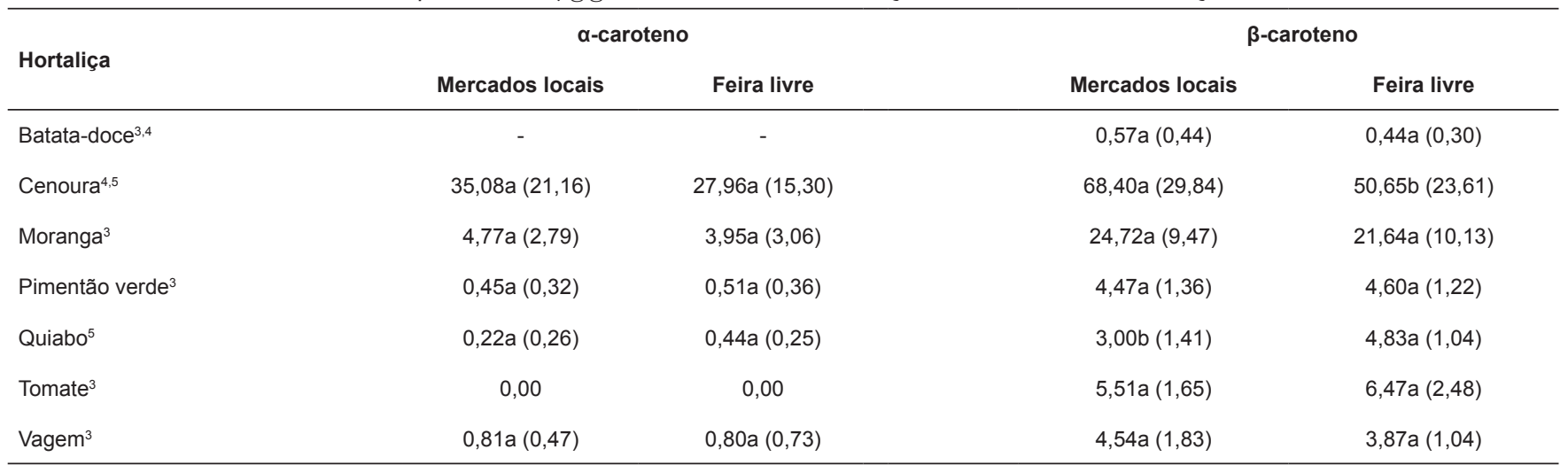

${ }^{1}$ Média das amostras analisadas durante primavera, verão e outono. ${ }^{2}$ Valores entre parênteses correspondem à estimativa do desvio-padrão. ${ }^{3}$ Médias de $\alpha$-caroteno e $\beta$-caroteno seguidas pela mesma letra na linha não diferem entre si pela análise de variância $(\mathrm{P} \geq 0,05) .{ }^{4} \mathrm{~A}$ quantificação do $\alpha$-caroteno não foi realizada em razão dos baixos níveis detectados. ${ }^{5}$ Médias de $\beta$-caroteno seguidas pela mesma letra na linha não diferem entre si pelo teste de Duncan $(\mathrm{P} \geq 0,05)$ 


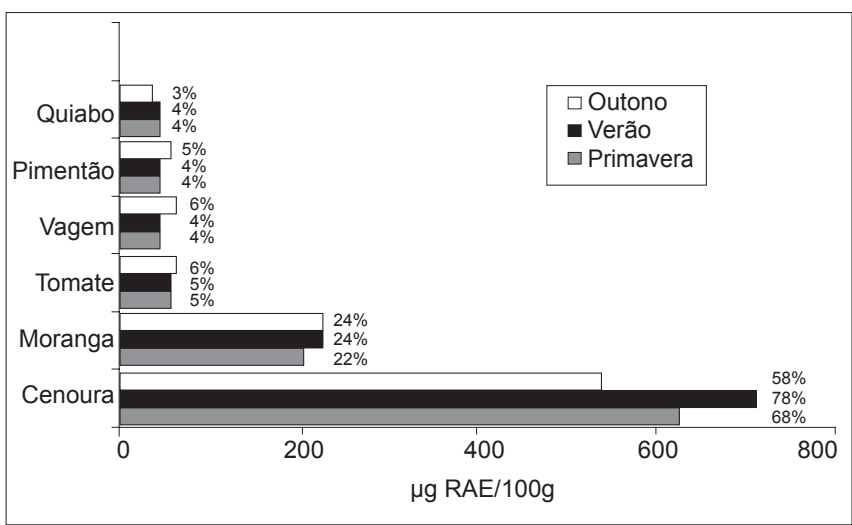

FIGURA 2 - Média do valor de vitamina A total em três estações do ano ( $\mu \mathrm{g}$ RAE/100 g) e adequação de vitamina A (\%) para adultos do sexo masculino

100 g das hortaliças foi calculada segundo a recomendação diária de vitamina A (900 $\mu \mathrm{g}$ RAE) para indivíduos adultos do sexo masculino entre 19 e 50 anos [12].

Como já era esperado, a variação dos valores de vitamina A entre os estabelecimentos comerciais e entre as estações do ano seguiu um perfil semelhante à variação encontrada para o conteúdo de $\beta$-caroteno, uma vez que este foi o principal carotenóide precursor de vitamina A nas hortaliças pesquisadas, além da sua maior capacidade de conversão em vitamina $\mathrm{A}$, em relação aos demais carotenóides pró-vitamínicos A. Um estudo realizado nos EUA, que analisou hortaliças provenientes de cinco cidades diferentes, em três meses (novembro, março e julho), também não encontrou variação significativa no valor de vitamina A das hortaliças entre os meses de estudo, nem entre os locais de coleta [5].

Os resultados sugerem que, com exceção da batata-doce, todas as hortaliças analisadas são boas fontes de carotenóides pró-vitamínicos A. Como boa parte da população depende dos alimentos vegetais para suprir suas necessidades de vitamina A, é interessante calcular quanto custa ingerir as quantidades de RAE recomendadas pelo IOM [12]. Levando-se em conta a cenoura, pode-se calcular que $1 \mathrm{~kg}$ da hortaliça custa, em média, atualmente, R\$ 1,00; assim sendo, 100 g custariam R\$ 0,10 . De fato, $100 \mathrm{~g}$ de cenoura crua podem fornecer, em média, $627 \mu \mathrm{g}$ RAE. Atingir a recomendação de vitamina A para um indivíduo adulto do sexo masculino custaria, em média, R\$ 0,14 /dia ou R\$ 4,30 ao mês. Considerando um alimento de origem animal, como o leite fortificado com vitamina A, que, segundo o fabricante, tem $240 \mu \mathrm{g}$ de RAE/100 g, seria necessário consumir $375 \mathrm{~mL}$ do mesmo para atingir a recomendação de vitamina A. Atualmente, o preço médio de $1 \mathrm{~L}$ de leite fortificado é de RS 1,20. Portanto, $375 \mathrm{~mL}$ custariam aproximadamente RS 0,45; totalizando R\$ 13,50 mensais (em torno de $314 \%$ a mais).

Conforme apresentado, porções de cerca $100 \mathrm{~g}$ das hortaliças analisadas fornecem uma adequação de vitamina A entre 3 e 78\%, em relação à recomendação [12]. Sendo assim, o consumo de três a quatro porções diárias dessas hortaliças, conforme é largamente recomendado, poderia contribuir com uma boa parcela do total de vitamina A consumido diariamente, ainda que na prática, as porções consumidas sejam menores que $100 \mathrm{~g}$.

Além disso, mesmo não havendo, ainda, uma recomendação do IOM para carotenóides, o consumo de hortaliças fontes destes é amplamente recomendado, devido às evidências epidemiológicas de sua ação na redução do risco de doenças crônico-degenerativas [12].

\section{4 - CONCLUSÕES}

$\mathrm{O} \alpha$-caroteno não foi detectado nas amostras de tomate e não foi determinado nas amostras de batata-doce devido às reduzidas quantidades encontradas. As amostras de cenoura apresentaram os conteúdos mais elevados, tanto de $\alpha$-caroteno quanto de $\beta$-caroteno. Por outro lado, a batatadoce apresentou os valores mais reduzidos de $\beta$ caroteno.

Em geral, o tipo de estabelecimento para comercialização não ocasionou variação do conteúdo de $\alpha$ e $\beta$-caroteno das hortaliças. Apenas a cenoura oriunda dos mercados formais apresentou um conteúdo de $\alpha$ e $\beta$-caroteno significativamente maior, enquanto o quiabo proveniente da feira livre apresentou os teores mais elevados. A variação climática entre primavera, verão e outono não mostrou ter influência significativa no conteúdo de $\alpha$ e $\beta$-caroteno das hortaliças analisadas, com exceção do pimentão verde, coletado no outono, que apresentou teores estatisticamente mais elevados de $\beta$-caroteno.

TABELA 5 - Contribuição das pró-vitaminas A ( $\alpha$ e $\beta$-caroteno) para o valor de vitamina A total das hortaliças analisadas

\begin{tabular}{|c|c|c|c|c|}
\hline \multirow{3}{*}{ Hortaliça } & \multicolumn{4}{|c|}{ Média $^{3}$ do valor de vitamina A ( $\mu$ g RAE/100 g) } \\
\hline & \multicolumn{2}{|c|}{ Mercados $^{1}$} & \multicolumn{2}{|c|}{ Feira livre $^{2}$} \\
\hline & $\alpha$-caroteno & $\beta$-caroteno & $\alpha$-caroteno & $\beta$-caroteno \\
\hline Batata-doce & - & $4,80(3,70)$ & - & $3,70(2,52)$ \\
\hline Cenoura & $146,18(88,17)$ & $570,05(248,68)$ & $116,50(63,77)$ & $422,05(196,80)$ \\
\hline Moranga & $16,45(11,63)$ & $205,98(78,93)$ & $19,88(12,76)$ & $180,30(84,45)$ \\
\hline Pimentão verde & $1,89(1,34)$ & $37,27(11,34)$ & $2,13(1,50)$ & $38,31(10,15)$ \\
\hline Quiabo & $0,91(0,59)$ & $25,01(11,72)$ & $1,83(1,03)$ & $40,27(8,64)$ \\
\hline Tomate & 0,00 & $45,89(13,72)$ & 0,00 & $53,94(20,69)$ \\
\hline Vagem & $3,89(1,97)$ & $37,80(15,28)$ & $3,34(3,04)$ & $30,77(8,69)$ \\
\hline
\end{tabular}

${ }^{1}$ Valores correspondem à média dos mercados 1 e $2 .{ }^{2}$ Valores correspondem à média dos pontos de coleta (bancas) $1,2,3,4$ e 5 da feira livre. ${ }^{3}$ Valores entre parênteses correspondem à estimativa do desvio-padrão 
Destaca-se que, com exceção da batata-doce, as hortaliças em estudo mostraram ser boas fontes de carotenóides pró-vitamínicos $\mathrm{A}$, podendo contribuir para uma ingestão adequada da vitamina. Como estas hortaliças estão disponíveis em grande parte do ano e seu custo é acessível, especialmente para populações mais carentes, sugere-se o seu consumo freqüente, uma vez que elas podem contribuir para reduzir a deficiência de vitamina A.

\section{6 - REFERÊNCIAS BIBLIOGRÁFICAS}

[1] ABUSHITA, A.A.; DAOOD, H.G.; BIACS, P.A. Change in Carotenoids and antioxidant vitamins in tomato as a function of varietal and technological factors. J. Agric. Food Chem., v. 48, p. 2.075-2.081, 2000.

[2] ALMEIDA, L. B.; PENTEADO, M.C.V. Carotenoids and pro-vitamin A value of white fleshed Brazilian sweet potatoes (Ipomoea batatas Lam.). J. Food Composition Anal., v. 1, p. 341-352, 1988.

[3] ARIMA, H.K.; RODRIGUEZ-AMAYA, D.B. Carotenoid composition and vitamin A value of a squash and a pumpkin from Northeastern Brazil. Arch. Latinoam. Nutr., v. 40, p. 284-292, 1990.

[4] BENDICH, A. Carotenoids and the imune response. J. Nutr., v. 119, p. 112-115, 1989.

[5] BUREAU, J.L. \& BUSHWAY, R.J. HPLC Determination of carotenoids in fruits and vegetables in the United States. J. Food Sci., v. 51, n. 1, p. 128-130. 1986.

[6] GIUNTINI, D.; GRAZIANI, G.; LERCARI, B.; FOGLIANO, V.; SOLDATINI, G.F.; RANIERI, A. Changes in carotenoid and ascorbic acid contents in fruits of different tomato genotypes related to the depletion of UV-B radiation. J. Agric. Food Chem., v. 53, p. 3.174-3.181, 2005.

[7] GODOY, H. T. \& RODRIGUEZ-AMAYA, D. Occurrence of cis isomers of provitamins A in brazilian vegetables. J. Agric. Food Chem., v. 46, p. 3.081-3.086, 1998.

[8] GRANADO, F.; OLMEDILLA, B.; BLANCO, I.; ROJASHIDALGO, E. Carotenoid composition in raw and cooked spanish vegetables. J. Agric. Food Chem.,v. 40, p. 2.135-2.140. 1992.

[9] HART, D.J. \& SCOTT, K.J. Development and evaluation of na HPLC method for the analysis of carotenoids in foods, and the measurement of the carotenoid content of vegetables and fruits commonly consumed in the UK. Food Chem., v. 54, p. 101-111, 1995.

[10] HEINONEN, M.; OLLILAINEN, V.; LINKOLA, E.; VARO, P.; KOIVISTOINEN, P. Carotenoids in finnish foods: vegetables, fruits, and berries. J. Agric. Food Chem., v. 37, p. 655-659, 1989.

[11] HOLDEN, J.M.; ELDRIDGE, A.L.; BEECHER, G.R.; BUZZARD, M.; BHAGWAT, S.; DAVIS, C.S. DOUGLASS, L.W.; GEBHARDT, S.; HAYTOWITZ, D.; SCHAKEL, S. Carotenoid content of U.S. foods: an update of the database. J. Food Composition Anal., v. 12, p. 169196, 1999.

[12] IOM - U. S. Institute of Medicine, Food and Nutrition Board, Standing Committee on the Scientific Evaluation of Dietary Reference Intakes. Dietary Reference Intakes: for Vitamin $A$, Vitamin $K$, Arsenic, Boron, Cromium, Copper, Iodine, Iron,
Manganese, Molybdenium, Nickel, Silicon, Vanadium and Zinc. Washington, D.C., National Academy Press, 797 p. 2001.

[13] KHACHIK, F; GOLI, M.B.; BEECHER, G.R.; HOLDEN, J.; LUSBY, W.R.; TENORIO, M.D.; BARRERA, M.R. Effect of food preparation on qualitative and quantitative distribution of major carotenoid constituents of tomatoes and several green vegetables. J. Agric. Food Chem., v. 40, p. 390-398, 1992.

[14] K'OSAMBO, L.M.; CAREY, E.E.; MISRA, A.K.; WILKES, J.; HAGENIMANA, V. Influence of age, farming site and boiling on provitamin A content in sweet potato (Ipomoea batatas (L.) Lam.) storage roots. J. Food Composition Anal., v. 11, p. 305-321, 1998.

[15] OLSON, J.A. In: MACHLIN, L.J., ed. Handbook of Vitamins. $2^{\mathrm{a}}$ ed. New York, Marcel Dekker, p. 1-57. 1991.

[16] PINHEIRO-SANT'ANA, H.M.; STRINGHETA, P.C.; BRANDÃO, S.C.C.; AZEREDO, R.M.C. Carotenoid retention and vitamin A value in carrot (Daucus carota L.) prepared by food service. Food Chem., v. 61 (1-2); p.145-151, 1998.

[17] RAMAKRISHNAN, U. Prevalence of micronutrient malnutrition worldwide. Nutr. Rev., v. 60, p. 46-52, 2002.

[18] RAMALHO, R.A.; FLORES, H.; SAUNDERS, C. Hipovitaminose A no Brasil: um problema de saúde pública. Rev. Saúde Pública, v. 34, n. 1, p. 56-63, 2002.

[19] RODRIGUEZ, D.B.; RAYMUNDO, L.C.; LEE, T.; SIMPSON, K.L.; CHICHESTER, C.O. Carotenoid pigment changes in ripening Momordica charantia fruits. Ann. Bot., v. 40, p. 615-624, 1976.

[20] RODRIGUEZ-AMAYA, D.B. A guide for carotenoids analysis in foods. Washington, DC: International Life Sciences Institute Press. 1999.

[21] RODRIGUEZ-AMAYA, D.B. Carotenoids and food preparation: the retention of provitamin A carotenoids in prepared, processed, and stored foods. 93 p. 1997.

[22] RODRIGUEZ-AMAYA, D.B. Critical review of provitamin A determination in plant foods. J. Micronutr. Anal., v. 5, p. 191-225, 1989.

[23] RODRIGUEZ-AMAYA, D.B. Nature and distribution of carotenoids in foods. In: CHARALAMBOUS, F. ed. Shelf life of foods and beverages - chemical biological, phisical and nutritional aspects. Amsterdam, Elsevier Science, p. 547-589. 1993.

[24] RODRIGUEZ-AMAYA, D.B. Some considerations in generating carotenoid data for food composition tables. J. Food Composition Anal., v. 13, p. 641 647, 2000.

[25] SAS Institute Inc. SAS/STAT User's Guide. version 6, fourth edition, v. 2, Cary, NC: SAS Institute Inc., 846 p, 1994.

[26] SOUZA, W.A.; VILAS BOAS, O.M.G.C. A deficiência de vitamina A no Brasil: um panorama. Rev. Panam. Salud Publica, v. 12, n. 3, p. 173-179, 2002.

[27] TAPIERO, H.; TOWNSEND, D.M.; TEW, K.D. The role of carotenoids in the prevention of human pathologies. Biomedicine \& Pharmacotherapy, v. 58, p. 100-110, 2004.

[28] WEST JR, K.P. Extent of vitamin A deficiency among preschool children and women of reproductive age. 
J. Nutr., v. 132, p. 2857S-2866S, 2002.

[29] WILBERG, V.C. \& RODRIGUEZ-AMAYA, D.B. Quantificação de alguns dos seus produtos por Cromatografia Líquida de Alta Eficiência. Ciên. Tecnol. Aliment., v.
13, n. 2, p. 132-141, 1993.

[30] ZIEGLER, R.G., A review of epidemiologic evidence that carotenoids reduce the risc of cancer. J. Nutr., v. 119, p. 116-122, 1989. 